\title{
Influência da crise financeira de 2008: uma análise sobre a tecnologia da informação dos maiores bancos do consolidado financeiro brasileiro (2001-2016)
}

\author{
Rosa Livia Gonçalves Montenegro \\ Universidade Federal de Juiz de Fora - Juiz de Fora - Minas Gerais - Brasil \\ ORCID: https://orcid.org/0000-0001-8383-5131 \\ Mariana Carolina da Silva \\ Universidade Federal de São João del Rei - São João del Rei - Minas Gerais - \\ Brasil \\ ORCID: https://orcid.org/0000-0002-4574-8958 \\ Fernanda Espiridião \\ Universidade Federal de Sergipe - Aracaju - Sergipe - Brasil \\ ORCID: https://orcid.org/0000-0002-8580-2090 \\ Douglas Marcos Ferreira \\ Universidade Federal de São João del Rei - São João del Rei - Minas Gerais - \\ Brasil \\ ORCID: https://orcid.org/0000-0002-1905-7555
}

\section{Resumo}

Este artigo tem por intuito analisar os efeitos da tecnologia de informação (TICs) sobre a funcionalidade no sistema financeiro brasileiro baseando-se na abordagem Pós-Keynesiana e Neo-Schumpeteriana. A partir da abordagem Pós Keynesiana, buscou-se identificar as contribuições das TICs nos fatores de produção no sistema bancário, como a seleção de variáveis estratégicas dos bancos brasileiros no período de recessão. Por intermédio da metodologia de análise de dados em painel, durante os anos de 2001 a 2016, obteve-se resultados que captaram os efeitos e a repercussão da crise de 2008 sob o sistema bancário brasileiro. A partir dos principais resultados da estimação observou-se que o valor da sensibilidade das inovações financeiras foi superior ao fator de produção trabalho e, durante o período, a criação de inovações financeiras representou maior relevância quanto aos aspectos da redução de custos pelas instituições financeiras brasileiras sob análise.

Palavras-chave: Tecnologia da informação e comunicação. Crise financeira global. Sistema bancário brasileiro. Teoria Pós-Keynesiana. 


\title{
Influence of the 2008 financial crisis: an analysis of the information technology of the largest banks in the Brazilian financial consolidated (2001-2016)
}

\begin{abstract}
This article aims to analyze the effects of information technology (ICTs) on functionality in the Brazilian financial system based on the Post-Keynesian and Neo-Schumpeterian approach. From the Post Keynesian approach, we sought to identify the contributions of ICTs to the factors of production in the banking system, such as the selection of strategic variables of Brazilian banks in the recession period. Through the panel data analysis methodology, during the years 2001 to 2016, results were obtained that captured the effects and repercussions of the 2008 crisis on the Brazilian banking system. From the main estimation results, it was observed that the value of the sensitivity of financial innovations was higher than the factor of labor production and, during the period, the creation of financial innovations represented greater relevance in terms of cost reduction aspects by Brazilian financial institutions under analysis.

Keywords: Information and Communication Technology. Global Financial Crisis. Brazilian Banking System. Post-Keynesian Theory.

\section{Influencia de la crisis financiera de 2008: un análisis de la tecnología de la información de los bancos más grandes en el consolidado financiero brasileño (2001-2016) \\ Resumen}

Este artículo tiene como objetivo analizar los efectos de las tecnologías de la información (TIC) en la funcionalidad del sistema financiero brasileño con base en el enfoque pos keynesiano y neo schumpeteriano. Desde el enfoque pos keynesiano, se buscó identificar las contribuciones de las TIC a los factores de producción en el sistema bancario, como la selección de variables estratégicas de los bancos brasileños en el período de recesión. A través de la metodología de análisis de datos de panel, durante los años 2001 a 2016, se obtuvieron resultados que capturaron los efectos y repercusiones de la crisis de 2008 en el sistema bancario brasileño. De los principales resultados de la estimación, se observó que el valor de la sensibilidad de las innovaciones financieras fue superior al factor de producción laboral y, durante el período, la creación de innovaciones financieras representó mayor relevancia en términos de aspectos de reducción de costos por parte de las instituciones financieras brasileñas bajo análisis.
\end{abstract}

Palabras clave: Tecnología de la información y la comunicación. Crisis financiera global. Sector bancario brasileño. Teoría post keynesiana.

\section{Introdução}

Por volta da década de 1970 houve um rápido avanço tecnológico, e esse período ficou conhecido como a quinta revolução tecnológica, dentro do âmbito econômico as inovações tecnológicas permitem a ampliação de lucros por meio de operações complexas, além de promover a flexibilização do gerenciamento e da administração dos balanços patrimoniais das instituições financeiras, como os bancos (REZENDE, 2012). Após o ano 2000, houve a proliferação do uso da internet no mundo, em que as empresas tiveram que se adequar e direcionar de forma mais eficiente possível ao uso das Tecnologias da Informação e Comunicação (TICs). 0 uso das TICs exerce função direta e positiva no crescimento das firmas e na estratégia de concorrência de mercado (MAINETTI, GRAMANI E BARROS, 2014).

Rezende (2012) conceitua que as TICs abrangem uma variedade de sistemas, dispositivos e serviços no processamento de softwares e hardwares, que permitiram nova forma de organização em todos os setores da economia. A globalização e a desregulamentação dos mercados acentuaram as relações econômicas. Sendo assim, o setor bancário investiu muito no progresso tecnológico, e as TICs tornaram-se fundamentais para produzir financiamentos, 
serviços de depósitos e pagamentos, além das vantagens competitivas e diminuir a assimetria de informação. (REZENDE, 2012).

Dentro do arcabouço teórico buscou-se a interação das teorias Neoschumpeteriana e Pós-Keynesiana, enquanto a primeira abordagem atribui a relevância da inovação no desenvolvimento econômico, a segunda revela a importância do sistema financeiro na economia, além de descrever o comportamento dos agentes em períodos de crise. Ambos os autores concordam que o mercado não é autorregulado e que, as expectativas de longo prazo estão intrinsecamente ligadas a incerteza, que nesse caso torna-se arriscado, pois ativos com inovação e investimento produtivo estão a um nível alto de incerteza. (PAULA, 2014).

Nesse sentido, a crise imobiliária nos Estados Unidos tornou-se gradativamente perigosa ao sistema financeiro mundial, e ameaçou estagnar o crescimento e o desenvolvimento dos demais países. Dissemelhante das outras crises, a recessão de 2008 teve características singulares, a inovação nos mercados de derivativos e o paradigma das taxas de juros, tanto no curto quanto no longo prazo, incentivaram os investidores a diversificarem suas carteiras em busca de rentabilidade, com o excesso de liquidez no mercado, o mercado imobiliário estadunidense se tornou alvo das especulações, uma crise inédita no mercado de derivativos.

De acordo com a abordagem Pós Keynesiana, buscou-se identificar as contribuições das TICs nos fatores de produção no sistema bancário, como as variáveis estratégicas dos bancos brasileiros em período de recessão como: a receita operacional, patrimônio líquido, valores de títulos mobiliários, lucro líquido, número de funcionário e agências. Por meio da construção de dados em painel com base em uma amostra de 18 (dezoito) bancos analisados, durante o primeiro trimestre do ano de 2001 até o quarto trimestre de 2016, totalizando uma amostra com 64 períodos de tempo, foi estimada uma regressão pelo método dos mínimos quadrados ordinários. Ressaltando também os efeitos e a repercussão da crise de 2008 no sistema bancário brasileiro.

Além desse da introdução, esse trabalho se organiza em mais 5 itens. $\mathrm{Na}$ seção 2, será tratado a teoria pós keynesiana e a inovação tecnológica sob a abordagem neo-schumpteriana. No item seguinte, serão discutidas as perspectivas da crise de 2008 nos EUA e seu impacto no Brasil. Na quarta seção serão detalhadas a base de dados e a metodologia aplicada, a saber, dados em painel. Por fim, nas seções 5 e 6, são tecidas as conclusões do trabalho, salientando as contribuições e os principais resultados sob o efeito financeiro da crise mundial no ano de 2008.

\section{Teoria Pós Keynesiana: um breve resumo}

A teoria Pós-Keynesiana trouxe uma nova versão para a interpretação do papel das instituições exercidos na economia, especialmente para o sistema financeiro, entre eles o funcionamento bancário. Já de acordo com a teoria Neoclássica, as instituições exercem papel de neutralidade no sistema financeiro pois estas apenas intermediam os recursos entre os poupadores e os investidores. Entretanto, Keynes, em sua obra Teoria Geral do Emprego, dos Juros e da Moeda (1988), demonstra que o sistema bancário não cria moeda 
apenas para atender a necessidade de meios pagamentos, mas acrescenta a função de crédito. Essa nova função creditícia da moeda é essencial para o financiamento dos investimentos nas economias capitalistas, as instituições bancárias têm o poder de decidir a quantidade de crédito que será destinada aos diferentes tipos de investimentos disponíveis. Sendo assim, as estratégias bancárias têm ligações diretas sobre o desempenho das variáveis reais na economia. (REZENDE, 2012).

Fez-se necessário analisar os desdobramentos da economia monetária pela visão Pós-Keynesiana, para isso será incluído autores como Minsky (2010), Stuart (1995) e Paula (2008). Mesmo com divergências entre alguns autores citados, em determinados temas, todos convergem para a importância do sistema bancário para o desenvolvimento e crescimento econômico dos países.

Minsky (2010) inclui a teoria dos ativos de Keynes, a administração das estruturas patrimoniais, para explicar a funcionalidade do sistema financeiro na economia fundamentada no circuito financiamento-investimento-poupançafunding ${ }^{1}$. Esse circuito compreende que o sistema financeiro é mais do que um simples intermediário entre poupadores e investidores. De acordo com Stuart (1995), as instituições financeiras são responsáveis por financiar os investimentos produtivos que geram poupança, que por sua vez resultam em um processo de criação de renda e dão base ao processo de crescimento econômico. Em suma, o financiamento ao investimento em geral está condicionado à existência de mecanismos de consolidação financeira, tanto do ponto de vista das instituições financeiras quanto dos investidores produtivos.

A principal crítica keynesiana à teoria neoclássica ${ }^{2}$ está relacionada ao princípio da não neutralidade da moeda no curto e no longo prazo. A moeda é um ativo que afeta as decisões dos agentes e, a demanda por moeda se deve pelo número de transações, pela especulação, por precaução e pelos financiamentos. Segundo Keynes (1988), a moeda é um meio de conservação de riqueza, e garante aos agentes, poder de compra futuro ressaltando as condições de incerteza que devem ser analisadas.

Por outro lado, os pós-keynesianos abordam o sistema bancário como uma firma, igual a qualquer outra, tendo assim, preferência pela liquidez com base em suas expectativas sobre um futuro incerto. Os bancos são vistos como agentes ativos que administram ao mesmo tempo, os dois lados de seus balanços patrimoniais, uma firma com expectativas e motivações próprias. Desse modo, esse tipo de instituição financeira tem impacto decisivo sobre as condições de financiamento da economia e sobre o nível de gastos dos agentes, afetando assim as variáveis reais da economia, como produto e emprego. (PAULA, 1999).

\footnotetext{
${ }^{1} \mathrm{O}$ finance, em conjunto com o funding, é o pilar que sustenta funcionalidade do sistema financeiro na economia. (REZENDE, 2012).

${ }^{2}$ A teoria neoclássica considera que, variáveis reais afetam variáveis reais e variáveis monetárias afetam variáveis monetárias. A não neutralidade da moeda também é defendida pelo Schumpeter. Para ele, a moeda não e apenas um meio para facilitar a circulação dos bens, mas também uma operação de extensão do crédito. (REZENDE, 2012).
} 
O tamanho da oferta de financiamento sofre variação de acordo com o portfólio de cada banco, que está estritamente ligado à incerteza. Isso porque a incerteza influencia diretamente sobre os critérios bancários na escolha do portfólio, já que operam com capital de terceiros. Para AIDAR (2015), a maior disponibilidade de recursos financeiros possibilita a firma obter mais efetividade em seus investimentos quando comparada aos seus concorrentes. Assim, espera-se que uma firma de maior porte tenha mais capacidade de geração de capital interno e maior acesso ao externo, o que o confere vantagem na obtenção de recursos financeiros em relação às firmas de menor porte. Esse tipo de comportamento dos bancos baseia-se na preferência pela liquidez para administrar a composição do balanço patrimonial. Assim, a preferência pela liquidez elucida as estratégias e decisões na escolha de ativos na composição das contas bancárias. (REZENDE, 2012).

É oportuno ressaltar que o setor bancário é responsável pelo comportamento cíclico da economia. O crescimento do financiamento na fase expansionista produz dois efeitos concomitantes: a atividade econômica com seu ritmo expandido e a fragilidade financeira que aumenta consideravelmente. Consequentemente, a economia passaria por um trade-off: quanto maior o ritmo de crescimento, menor será a resistência da economia a choques adversos, mesmo com mecanismos que possam auxiliar na redução das externalidades e dos ricos, gerando situações de enorme vulnerabilidade: as crises. (PAULA, 2008).

\subsection{Inovação tecnológica e abordagem neo-schumpeteriana}

Para aprofundar na proposta da análise das TICs no sistema financeiro, foi necessário relacionar a abordagem neo-schumpeteriana e a pós-keynesiana. Enquanto a primeira salienta a relevância da inovação na dinâmica do desenvolvimento econômico, a outra destaca a importância do sistema financeiro no desenvolvimento econômico. Em ambas as teorias o mercado não é autorregulado, sendo assim a incerteza tem ligação direta quanto as decisões relacionadas às expectativas de longo prazo, como inovação e investimento. As forças da inovação neo-schumpteriana e as forças financeiras pós-keynesianas são de natureza interruptiva na economia. (PAULA, 2014 ).

Tanto Keynes quanto Schumpeter ressaltam a importância do comportamento das empresas e das instituições para analisar a incerteza e a irreversibilidade do tempo. Enquanto a teoria pós-keynesiana prioriza a moeda, a teoria neo-schumpeteriana enfatiza a inovação. Outra divergência entre as abordagens é em relação às propriedades da moeda, Schumpeter acreditava que a moeda tinha apenas a função de meio de pagamentos, sendo assim, não explorava a preferência pela liquidez dos agentes. (ERBER, 1998).

A tecnologia da informação e comunicação diminuiu os custos das transmissões de informações e das transações financeiras, aumentando a rapidez no processamento de dados. Nesse sentido a firma é o local onde uma ou várias transformações tecnológicas são processadas em um determinado bem ou serviço. A firma é representativa, cujo gerente age racionalmente, com intuito de maximizar lucro, considerando a informação perfeita entre os agentes. Ela compra insumos 
(inputs, fatores de produção), combina-os segundo um processo de produção escolhido e vende produtos (outputs) no mercado. A firma é compreendida como um mero agente maximizador de lucros.

O sistema bancário é o setor que mais tem investido em tecnologia da informação, isso porque os produtos e serviços são estruturados pelas TICs. A alteração nos processos de produção, no novo tipo de interação com os clientes, requer o surgimento de novas tecnologias. De acordo com Rezende (2012), as informações são essenciais no processo de maturação dos ativos, e na transformação dos passivos com liquidez em ativos sem liquidez, mantendo a margem de segurança contra os riscos de crédito. Desse modo, cada instituição busca estratégias para administrar seu balanço, baseado na diminuição da assimetria da informação para amenizar os riscos e aumentar os lucros.

Pessali e Fernandez (2006) contribuíram para o entendimento do papel da tecnologia e do conhecimento no crescimento da firma. Eles interpretaram a firma como uma organização, na qual várias habilidades e o conhecimentos são reunidos na tentativa de produzir mercadorias. A capacidade da firma tanto de explorar habilidades e conhecimentos como em inovar é o que determina o quanto a firma pode crescer.

Schumpeter (1988) traz a definição de inovação como sendo uma aplicação industrial ou comercial de algo novo, novos produtos e processos, novos tipos de organização ou novos mercados. Ainda ressalta a importância da inovação como estímulo primário essencial para o processo de desenvolvimento econômico. Segundo o autor, o fluxo circular da economia corresponde a um estado estacionário, em que existe equilíbrio entre os produtores e consumidores, portanto, a moeda e o crédito não têm importância, e não existe inovação. Mas ao incluir a inovação no sistema financeiro, desloca-se a função de produção no fluxo circular, abrindo novas perspectivas sobre os lucros. (SCHUMPETER, 1988).

Com relação ao crédito, ele seria um dos elementos necessários para o crescimento da inovação, quando a mesma não pode ser realizada com seus próprios meios de produção. Tanto Schumpeter como Keynes afirmam que a oferta de crédito oferecida pelas instituições financeiras não depende da existência antecedente de poupança. (PAULA, 2014).

O investimento por sua vez, é determinado pelas expectativas de longo prazo relacionadas às rendas futuras de seus ativos de capital. Considerando o mundo como incerto, o sucesso dos negócios depende da validação das expectativas empresariais. Desse modo, o investimento só será realizado se o animal spirit dos empresários estiver desperto, e se conjuntamente houver disponibilidade de crédito por parte do setor bancário. Em uma economia monetária, a oferta agregada de financiamento é estabelecida pelo desejo dos bancos de criar crédito e depósitos correspondentes, e pelo estoque de moeda existente. (KEYNES, 1988).

Portanto, as TICs como qualquer outra inovação tecnológica têm seus custos elevados, demanda um alto volume de recursos, e seu retorno ao longo do tempo é incerto. Paula (2014) discorre que, a implementação da inovação da tecnologia dependa da natureza e dos interesses das instituições, dos fatores institucionais, dos processos de tentativa e erro na exploração da nova 
tecnologia e das possibilidades determinadas pelas oportunidades do progresso técnico. Um elemento agravante aos custos referente a instalação de novas tecnologias é que, tais investimentos têm incerteza não probabilística, dificultando a previsão no mínimo segura para a tomada de decisão. Além do mais, ativos intangíveis não têm garantia de crédito, pois são de difícil mensuração. (PAULA, 2014).

\section{3- A perspectiva da crise de 2008 nos EUA e o impacto no Brasil}

Em meados da década de 1990, ocorreu uma abertura de capital de diversas empresas do setor de tecnologia dos Estados Unidos, o que impulsionou muitas negociações na bolsa de valores. Foi um período em que se pode notar um crescimento bastante significativo, o mercado de renda estadunidense foi valorizado, possível consequência positiva das inovações tecnológicas aplicadas no sistema financeiro da época. Segundo Junior e Filho (2008), entre 1997 e 2006 os preços dos imóveis se elevaram de forma contínua, chegando mesmo a triplicar de valor. Esse processo foi impulsionado pelo aumento do crédito imobiliário americano, que esteve apoiado em taxas de juros baixas, particularmente após os atentados terroristas de 11 de setembro de 2001.

No ano de 2003, iniciou-se a crise imobiliária dos EUA, que foi se tornando gradativamente mais intensa ao decorrer dos anos, até eclodir no final do ano de 2007. Gerava-se, assim, um enorme dano ao sistema financeiro americano que afetou o crescimento econômico global. $O$ mercado de hipotecas norte-americano admitia a categoria subprime ${ }^{3}$, no qual, cedia empréstimos a pessoas que não tinham um bom histórico de crédito. Diante de um cenário favorável, surgiu a chamada securitização, que tinha como objetivo gerar oportunidades de curto prazo e flexibilização aos bancos, para que estes pudessem fornecer níveis altíssimos de empréstimos hipotecários de baixa qualidade. (ALBERINI; BOGUSZEWSKI, 2008).

De acordo com Junior, Rodrigues e Filho (2008), o problema começa quando os bancos compram as hipotecas subprimes das financeiras, e as aglomeram em carteiras com outros títulos dividindo de acordo taxa de juros e o nível de risco de cada uma. A securitização ao mesmo tempo em que deu aos bancos a possibilidade de amontoar suas carteiras de crédito em uma única negociação, vendendo os riscos de crédito para outros bancos e investidores, poderia conter uma armadilha. Isso porque, à medida que os bancos tiravam os riscos dos créditos de seus balanços patrimoniais, eles poderiam conceder maior volume de empréstimos com base no próprio capital, mas esse capital, não tinha alta liquidez. (MARRA; WERPEL, 2011).

\footnotetext{
3 Tradicionalmente, o mercado de hipotecas residenciais nos Estados Unidos era dominado pelo segmento prime, que conta com regras relativamente rígidas de avaliação de crédito e limites do valor a ser financiado. No entanto, existem ainda outras duas categorias de crédito: a alta classificação anterior entre a prime ou primeira linha - e o subprime - também conhecido como terceira linha. (ALBERINI; BOGUSZEWSKI, 2008).
} 
Com a integração financeira em crescimento desde o ano de 1980, a crise, que teve início no mercado hipotecário, logo se espalhou para diferentes mercados financeiros dos Estados Unidos e do restante do mundo. A incerteza em relação ao risco, fez com que os bancos tivessem preferência pela liquidez, diminuindo os empréstimos no mercado interbancário e reduzindo a concessão de crédito para os clientes, até mesmo os de baixo risco (Bresser-Pereira, 2010).

Diante desse cenário o sistema bancário americano ficou completamente comprometido, restringindo o grau de liquidez dos bancos. Percebendo o colapso causado pela bolha imobiliária, o FED (Federal Reserve) e os demais Bancos Centrais das maiores potências do mundo, como o Europeu, iniciaram como medida imediata, a redução das taxas de juros e forneceu liquidez nos mercados por meio de vários tipos de instrumentos, evitando a quebra imediata das instituições financeiras ou apenas retardando o processo de algumas delas.

O efeito sofrido pela crise americana no setor bancário brasileiro foi inicialmente a dificuldade de obtenção de fundos no mercado financeiro internacional, acrescido mais tarde pela derrocada das expectativas gerada pela percepção da gravidade da crise internacional. Desde 2004 que o setor bancário passava por uma expansiva oferta de crédito, tanto para pessoas físicas quanto para pessoas jurídicas, subindo a relação crédito totais PIB de $22 \%$ do PIB em maio de 2003 para $36 \%$ em junho de 2008. Contudo, o spread bancário médio sofreu redução de 50\% para 33\% de 2004 a 2008 respectivamente, mas essa queda não foi de fato relevante. $O$ arranjo entre maior volume de crédito com spreads ainda considerados elevados possibilitou que os bancos auferissem elevados lucros e receitas na intermediação financeira nesse estímulo a oferta de crédito. Sendo assim, cresceram tanto a carteira de crédito de grandes bancos varejistas quanto de pequenos bancos. (PAULA, 2008).

Após a falência do banco de investimento Lehman Brothers em meados de setembro de 2008 , todos os investidores de grande importância tomaram aversão aos riscos, como um "efeito dominó" a próxima consequência foi a desvalorização das moedas, principalmente dos países periféricos. Entre 15 de setembro e 15 de outubro do mesmo ano, o real se depreciou em $22,7 \%$, gerando fortes perdas para as empresas brasileiras que haviam realizado operações de derivativo de dólar no mercado de balcão no Brasil e no exterior. (DE FREITAS, 2009).

Desse modo, foi necessária a intervenção do governo brasileiro para frear o crédito e desacelerar a expansão da economia com o intuito de conter a inflação no país. Sendo assim, a primeira medida foi o recolhimento compulsório sobre os depósitos bancários das empresas de leasing. A segunda medida foi a elevação da meta da Selic para reforçar a disputa por recursos no mercado doméstico de capitais. No momento da elevação do custo de captação das empresas tanto no mercado internacional, quanto no mercado doméstico, alguns bancos passaram a oferecer empréstimos vinculados às operações com derivativos de dólar em condições de custo mais favoráveis para as empresas. (DE FREITAS, 2009). 
Portanto, dada a preferência pela liquidez ${ }^{4}$ dos bancos e a possibilidade de investir em títulos públicos, de maneira segura e rentável, os bancos privados preferiram não ampliar o crédito. A liquidez só voltou a circular no final do primeiro trimestre de 2009, quando o governo decidiu garantir, mediante o Fundo Garantidor de Crédito, os recibos de depósito bancário (RDB) até 20 milhões de reais por aplicador. Sendo assim, se não fosse à ação anticíclica dos bancos públicos, como o BNDES e a CEF (Caixa Econômica Federal), a retração da economia brasileira no último trimestre de 2008 teria sido ainda mais densa (DE FREITAS, 2009).

Quanto ao período da recessão que afetou o país em 2008, buscou-se identificar as contribuições das TICs nos fatores de produção no sistema bancário. A motivação dessa pesquisa está centrada na necessidade de um estudo mais profundo que compreenda o efeito da crise e das condições bancárias no Brasil sobre a eficiência tecnológica e suas inovações, no período compreendido entre os anos de 2001 e 2016.

\section{1 - Dinâmica regional do sistema bancário no Brasil}

Na presente seção, será possível compreender o papel caracterizado de acordo com o ponto de vista pós-keynesiano, pela imperfeita mobilidade de recursos entre as regiões brasileiras. Regiões com características políticas, históricoestruturais e economicamente distintas (Rodriguez-Fuentes e Dow, 2003) influenciam na caracterização de diferentes graus de desenvolvimento entre as localidades e despertam as vulnerabilidades nas regiões com menores potencialidades (SILVA, 2011). Do mesmo modo, a evolução do aprimoramento de novos processos produtivos e o desenvolvimento do setor de serviços e da esfera financeira tem alterado a dinâmica das relações entre as localidades. Tais mudanças exercem influência nos aspectos da facilidade de acesso à oferta e demanda por serviços e, requerem um maior nível de sofisticação e especialização, principalmente sob o ponto de vista tecnológico. Nesse aspecto, o setor bancário se destaca por desempenhar o desenvolvimento de serviços inovadores que passam a ser demandados pelo mercado. (FONSECA, MEIRELLES e DINIZ, 2010). Ressalta-se que a proximidade e a localização são elementos importantes tornando a troca de informações rápida, facilita o processo de compartilhamento e difusão do conhecimento entre elas. Isso ocorre não somente entre as firmas inovadoras que possuem seu próprio esforço em pesquisa, mas também a partir do compartilhamento do P\&D desenvolvido por outras instituições locais (MONTENEGRO, 2014).

Assim, as vantagens da concentração do setor bancário nos centros urbanos e a concentração de atividades produtivas nesse espaço são múltiplas e baseiam-se no conceito de economias de aglomeração (clusters). De acordo com Audretsch e Feldman, 1996), as economias de aglomeração possuem como aspecto central a

\footnotetext{
${ }^{4} \mathrm{Na}$ situação de elevada aversão ao risco e de empoçamento da liquidez nas instituições de maior porte, a manutenção da taxa de juros básica em patamar elevado piorou ainda mais as condições de crédito, tanto para empresas como para bancos de médio e pequeno porte, acelerando o caminho da economia brasileira para a recessão. (DE FREITAS,2009).
} 
proximidade territorial de agentes econômicos, políticos e sociais e, envolve diversos tipos de externalidades, que explicam tanto a aglomeração espacial da produção quanto das inovações, tendo em vista que as concentrações espaciais da produção e da inovação são muito correlacionadas (MARSHALL, 1982; WOOD, 2001).

Os fluxos de conhecimento provenientes nas grandes cidades são justificados por causa da grande concentração de profissionais qualificados no trabalho, fornecedores e grande quantidade de instituições de pesquisa regionais, tais como: universidades, associações comerciais e organizações de negócios locais, que podem ser definidos como uma forte conexão para as firmas, no que tange ao processo de conhecimento (AUDRETSCH, 1998). A interação entre as pessoas nas cidades na geração de novas ideias e produtos explica o processo de difusão da inovação financeira, por exemplo (JACOBS, 1969). A significativa contribuição das interações consiste na explicação de que a concentração de economias de aglomeração em áreas urbanas permite atingir maior eficiência estática reduzindo, assim, a incerteza e o risco do processo inovador

A partir da discussão introdutória sobre a dinâmica regional, observa-se que no caso brasileiro a realidade acaba dificultando os avanços tecnológicos em áreas com médio ou mínimo potencial de capacidade de absorção da tecnologia. É oportuno destacar alguns elementos que provocam esses gargalos como: as disparidades da desigualdade de renda, produtiva e econômica que acabam provocando um efeito que centraliza e concentra os serviços com maior sofisticação em centros de maior dinamismo econômico (SILVA, 2011).

\section{4- Metodologia}

\section{1- Dados em painel}

A metodologia que será utilizada no trabalho consistirá na técnica de dados em painel, pela estimação dos Mínimos Quadrados Ordinários (MQO) para dados em painel, efeito aleatório e efeito fixo, além dos testes de robustezes para a escolha do melhor modelo econométrico. Os modelos de regressão com dados em painel são também chamados de dados longitudinais ou dados combinados, por combinar o modelo de séries temporais e o modelo de corte transversal.

Para a coleta dos dados em painel, se faz o acompanhamento das mesmas variáveis ao longo do tempo. Não se pode supor que as observações sejam independentemente distribuídas ao longo do tempo, para isso modelos e métodos especiais foram desenvolvidos para analisar dados em painel. Uma das razões em se usar agrupamentos independentes de cortes transversais é, aumentar o tamanho da amostra. Ao agrupar amostras aleatórias extraídas da mesma população em períodos de tempo diferentes, obtêm-se estimadores mais precisos e estatísticas de testes mais robustas. Assim, o uso de dados com cortes transversais agrupados pode ser muito útil para avaliação do impacto de determinado evento ou decisão política (WOOLDRIDGE, 2014).

Cabe ressaltar que no modelo de dados em painel pode ocorrer problemas relacionados ao enviesamento de seleção. Especificamente, esse problema ocorre quando a captação dos dados não forma uma amostra aleatória. Sendo assim, 
ocorre o fenômeno das amostras truncadas, ou da auto seletividade, que podem ser considerados como efeitos não observados dentro dos dados construídos. Porém, uma vantagem do modelo em questão é que, há muito mais informação para se estudar o fenômeno pelos graus de liberdade adicionais (MONTENEGRO, DINIZ e SIMÕES, 2014).

O uso de dados em painel acrescenta uma nova dimensão de dificuldade ao problema da especificação do modelo: o termo de perturbação ou o termo de erro. Esse erro consiste em perturbações relativas à série temporal, aos dados em corte transversal e uma combinação desses dois modelos. O primeiro modo de utilizar os dados em painel seria combinar dados de corte transversal e séries temporais, como dito anteriormente, e estimar pelo método dos mínimos quadrados ordinários. A segunda técnica resulta no reconhecimento das variáveis omitidas e nas mudanças nos interceptos. O terceiro procedimento, leva em conta as perturbações em corte transversal e série temporal também pela estimação dos mínimos quadrados ordinários, mas de forma mais eficiente (PINDYCK e RUBINFELD, 2004).

Ademais, uma opção para modelar os efeitos não observados são os efeitos fixos e os efeitos aleatórios. No modelo de efeitos fixos a maior dificuldade encontrada é combinar os mínimos quadrados ordinários presumindo que o intercepto de inclinação é constante, a solução mais geral para esse problema e introduzir variáveis binárias que permitam ao termo de intercepto variar ao longo do tempo e das unidades. Já o modelo de efeitos aleatórios, inclui variáveis representativas sobre a falta de conhecimento do modelo, em que os termos de erro podem estar correlacionados ao longo do tempo e das unidades (PINDYCK e RUBINFELD, 2004).

Efeitos Fixos:

$\ddot{y_{i t}}=\beta_{1} \ddot{x_{i t}}+\ddot{u_{l t}}, t=1,2, \ldots, T$,

Efeitos aleatórios:

$y_{i t}=\beta_{0}+\beta_{1} x_{i t 1}+\cdots+\beta_{k} x_{i t k}+v_{i t} \quad(2)$

Caso o efeito não observado seja aleatório, isso não significa que o efeito aleatório será a melhor estimação a ser adotada. É necessário considerar se as variáveis não estão realmente correlacionadas. De modo contrário, se os efeitos não observados estão correlacionados com alguma variável explicativa, a estimação por efeitos fixos vai ser a mais apropriada. Para escolher o melhor método, é indicado realizar o teste de Hausman, entre os testes de efeitos fixos e aleatórios. (WOOLDRIDGE, 2014).

\section{2 - Base de dados}

Os dados utilizados foram obtidos através da pesquisa com dados do setor financeiro brasileiro, os mesmos foram coletados por meio do Banco Central do Brasil ( $B C B$ ), órgão do governo federal do Brasil vinculado ao Ministério da Fazenda. O Banco Central publica as informações contábeis de todos os bancos que estão ativamente em operação no Brasil nos anos analisados. Os dados são publicados trimestralmente desde os anos de 2000 e vem sendo atualizado até o momento, a plataforma que disponibiliza os dados pelo BCB chama-se de IF Data, e está acessível pela internet (BANCO CENTRAL DO BRASIL, 2017). Os bancos selecionados podem ser observados no Quadro 1. 
Quadro 1 - Instituições Bancárias utilizadas na amostra

\begin{tabular}{|c|c|c|c|}
\hline Nome da Instituição Bancária & Categoria & Tipo de Controle & $\begin{array}{ll}\text { Tipo } & \text { de } \\
\text { Documento } & \\
\end{array}$ \\
\hline ABC-BRASIL & $\begin{array}{l}\text { Banco especializado em } \\
\text { crédito }\end{array}$ & Privado Controle Estrangeiro & Conglomerado \\
\hline ALFA & Banco Comercial & Privado Nacional & Conglomerado \\
\hline BANESTES & Banco Múltiplo & Público Estadual & Conglomerado \\
\hline BANRISUL & Banco Varejista & Público Estadual & Conglomerado \\
\hline BB & Banco Varejista & Público Federal & Conglomerado \\
\hline $\begin{array}{l}\text { BCO DO NORDESTE DO BRASIL } \\
\text { S.A. }\end{array}$ & Banco Varejista & Público Federal & Independente \\
\hline BMG & $\begin{array}{l}\text { Banco especializado em } \\
\text { crédito }\end{array}$ & Privado Nacional & Conglomerado \\
\hline BRADESCO & Banco Varejista & Privado Nacional & Conglomerado \\
\hline BRB & Banco Varejista & Público Estadual & Conglomerado \\
\hline CAIXA ECONOMICA FEDERAL & Banco Varejista & Público Federal & Independente \\
\hline CITIBANK & Banco Varejista & Privado Controle Estrangeiro & Conglomerado \\
\hline DEUTSCHE & Banco Atacadista & Privado Controle Estrangeiro & Conglomerado \\
\hline FIBRA S.A. & Banco Múltiplo & Privado Nacional & Conglomerado \\
\hline ITAU & Banco Varejista & Privado Nacional & Conglomerado \\
\hline MERCANTIL DO BRASIL & Banco Varejista & Privado Nacional & Conglomerado \\
\hline RABOBANK INTL BRASIL S.A. & Banco Atacadista & Privado Controle Estrangeiro & Independente \\
\hline SAFRA & Banco Varejista & Privado Nacional & Conglomerado \\
\hline VOTORANTIM & Banco Atacadista & Privado Nacional & Conglomerado \\
\hline
\end{tabular}

Fonte: Elaboração própria com base nos dados obtidos pelo IF-Data Banco Central, 2018

O recorte temporal compreende o período do primeiro trimestre ano de 2001 ao quarto trimestre do ano 2016. Os relatórios divulgados contêm informações das instituições autorizadas a funcionar e que estejam em operação normal. Além disso, todos os relatórios têm periodicidade trimestral e são disponibilizados sessenta dias após o fechamento das datas-bases março, junho e setembro, e noventa dias após o fechamento da data base dezembro. Além disso, são categorizados como sendo de informações contábeis e de capital, o qual se destinou a construção da base de dados que utilizamos, além de informações de Crédito, de Câmbio e de Segmentação. (BANCO CENTRAL DO BRASIL, 2017).

Foi necessário definir durante todo o período de tempo a ser estudado, que as instituições bancárias fossem as mesmas. Sendo assim, da listagem disponibilizada pelo $\mathrm{BCB}$ que produz o ranking, todos os bancos autorizados a funcionar no país, sejam eles de capital nacional ou não, as dezoito instituições bancárias estavam listadas em todos os sessenta e quatro (64) trimestres do período compreendido entre o ano de 2001 a 2016. É necessário ressaltar que dessa classificação foi utilizado os bancos que se mantinham bem rankeadas na listagem.

Os bancos selecionados tinham por referência de classificação a variável Ativo - (menos) Intermediações, as variáveis utilizadas foram Receita Operacional, Lucro Líquido, Títulos de Valores Mobiliários, Patrimônio Líquido, Número de Funcionários e Número de Agências. Para a construção dos dados em painel, 
foram empilhadas as dezoito instituições em ordem alfabética para cada variável para os sessenta e quatro semestres. Após esse processo de filtragem das instituições bancárias e a construção das variáveis disponíveis, avançou-se nos itens subsequentes para o estudo das variáveis que melhor explicariam a influência da TIC no sistema bancário brasileiro no período da recessão de 2008.

\subsection{Estimação}

Estabelecidos os critérios da seleção da amostra e o período de dezesseis anos de estudo, o próximo passo é a estimação do modelo econométrico. Utilizouse a metodologia semelhante à de Rezende (2012), em outras palavras, uma função Cobb-Douglas para captar as contribuições da tecnologia da informação e comunicação, em termos da elasticidade dos fatores. A estimação irá mensurar a mudança de valor percentual do produto $Y$ devido a mudança percentual de cada insumo. A elasticidade é calculada da seguinte forma: $\frac{\ln Y}{\ln X}$, ou seja, em termos da elasticidade do produto para cada insumo. Assim, é possível configurar a equação da estimação econométrica:

Equação da estimação a ser utilizada:

$\ln Y_{i, t}=\ln \alpha_{0}+\alpha_{1} \ln E M P_{i, t}+\alpha_{2} \ln D T V M_{i, t}+\alpha_{3} \ln L L_{i, t}+\alpha_{4} \ln P T L_{i, t}+u_{i}$ (3)

A variável dependente $Y_{i, t}$ corresponde a receita operacional dos bancos, mensurando a produção de bens e serviços das instituições bancárias. A variável $E M P_{i, t}$ é o número de funcionários por agência, enquanto $D T V M_{i, t}$ representa os títulos, valores mobiliários e instrumentos derivativos, que serviram de proxy para as inovações financeiras. A referida variável seria uma ótima representação das inovações financeiras, já que, a negociação de títulos permitiu a criação de novos produtos e serviços por meio de do processo de securitização e dos instrumentos derivativos. Já $L L_{i, t}$ é a medida de eficiência do lucro líquido das instituições, e por fim, $P T L_{i, t}$ que mede a eficiência do patrimônio líquido dos bancos. $O$ termo de erro $u_{i}$, e $\alpha_{i}=\frac{\partial Y}{\partial X}$ o coeficiente das elasticidades. Esse produto marginal mede o quanto cada unidade do produto será aumentada pelo crescimento de uma unidade de insumo. Os subscritos nas variáveis representam o total da amostra, denotado por i, e o período de análise denotado por $t$, delimitando o horizonte de tempo de 2001 a 2016.

Diante das variáveis disponíveis e coletadas, foi necessário corrigir (deflacionar) os valores monetários pelo Índice Nacional de Preços ao Consumidor Amplo (IPCA) com base no ano de 2001 para todas as variáveis, exceto para o número de funcionários de agências. Para padronizar as variáveis elas foram divididas pelo número de funcionários, exceto a variável $E M P_{i, t}$. É oportuno ressaltar as contribuições das TICs nos fatores de produção no sistema bancário brasileiro antes, durante e depois do período da recessão de 2008, que também foram analisadas.

A primeira técnica para o uso de dados em painel combina dados em corte transversal e séries temporais e estima o modelo utilizando o método dos mínimos quadrados ordinários. Um segundo procedimento implicará o reconhecimento de 
que variáveis omitidas podem levar a mudanças nos interceptos para os dados em corte transversal e séries temporais (PINDYCK e RUBINFELD, 2004).

Quando um conjunto de dados em painel está "incompleto" em certos anos em pelo menos algumas unidades do corte transversal na amostra, chamamos o conjunto de dados em painel não equilibrado. Esse foi o caso do conjunto de dados em painel deste trabalho, em determinados trimestres observou-se a ausência de informação de algumas variáveis e, ao invés de 1.152 observações, obteve-se 1.038 no total. Porém, a mecânica de estimação dos efeitos fixos com um painel não equilibrado não é muito mais difícil que com um painel equilibrado. Se $T_{t}$ for o número de períodos de tempo da unidade i do corte transversal, simplesmente utiliza-se essas $T_{t}$ observações para fazer a centralização média. A regressão das variáveis dummies também é feita exatamente da mesma maneira como no caso do painel equilibrado, e os graus de liberdade são apropriadamente obtidos (WOOLDRIDGE, 2014).

Após o empilhamento dos dados foi preciso detectar se o modelo se comportaria em efeito fixo ou aleatório. Modelos com efeitos fixos acrescentam variáveis binárias para levar em conta esses interceptos que mudam. Uma terceira técnica que melhora a eficiência do primeiro processo de estimação por mínimos quadrados ordinários ao levar em conta perturbações em corte transversal e séries temporais, de acordo com Pindyck e Rubinfeld (2004). É importante ressaltar que as técnicas levam em conta o fato de que o termo de erro pode apresentar correlação ao longo do tempo e ao longo das unidades em corte transversal. (PINDYCK e RUBINFELD, 2004).

Desse modo, utilizou-se o teste de Hausman para a seleção do modelo entre as opções de efeitos fixos ou aleatórios. A hipótese nula foi rejeitada (Ho: efeitos aleatórios são consistentes e $\mathrm{H}$ 1: efeitos aleatórios não são consistentes), tendo como conclusão de que o modelo de efeitos aleatórios não é adequado, sendo preferível empregar o modelo de efeitos fixos e, nesse caso, as inferências estatísticas serão condicionadas a $\varepsilon_{i}$ na amostra.

Para o modelo de efeitos fixos, a dificuldade com a técnica de combinar os mínimos quadrados é que a pressuposição de intercepto e inclinação constantes pode não ser razoável. Sendo assim, se faz necessário introduzir variáveis binárias que permitam ao termo de intercepto variar ao longo do tempo e das unidades em corte transversal. Portanto, foram acrescidas duas variáveis dummy à equação inicial: D1 e D2, para categorizar o momento antes e pós crise das variáveis ao longo do período. Ademais, foram realizados testes para descobrir problemas como a auto correlação e a multicolinearidade que foram rejeitados, mas posteriormente, foi confirmada a heterocedasticidade no modelo. Contudo, o referido problema foi solucionado com a estimação do modelo robusto abaixo:

Equação da estimação final:

$\ln Y_{i, t}=\ln \alpha_{0}+\alpha_{1} \ln E M P_{i, t}+\alpha_{2} \ln D T V M_{i, t}+\alpha_{3} \ln L L_{i, t}+\alpha_{4} \ln P T L_{i, t}+D_{1}+D_{2}+u_{i}$ (4)

\section{5- Resultados}


Antes da análise das estimações econométricas, em que podem ser observados os resultados da estimação das elasticidades dos fatores de produção pela função CobbDouglas (Quadro 4), vale observar os resultados obtidos por intermédio das estatísticas descritivas, como a Matriz de Correlação (Quadro 2).

Quadro 2- Matriz de correlação

\begin{tabular}{|c|c|c|c|c|c|}
\hline Matriz de correlação & $\ln Y$ & $\operatorname{lnEMP}$ & $\operatorname{InDTVM}$ & $\operatorname{InPT}$ & $\operatorname{InLL}$ \\
\hline InY & 1.0000 & & & & \\
InEMP & 0.2578 & 1.0000 & & & \\
InDTVM & 0.4328 & 0.4413 & 1.0000 & & \\
InPT & 0.293 & 0.4393 & 0.5745 & 1.0000 & \\
InLL & 0.3164 & 0.4600 & 0.6441 & 0.8421 & 1.0000 \\
\hline
\end{tabular}

Fonte: Elaboração própria.

A matriz de correlação mostra os valores de correlação de Pearson, que medem o grau de relação linear entre cada par de itens ou variáveis. A matriz de correlação avaliará a força e a direção da relação entre dois itens ou variáveis. Os valores de correlação altos e positivos indicam que os itens medem a mesma habilidade ou característica. Se as variáveis não estão altamente correlacionadas, essas podem medir diferentes características ou podem não estar claramente definidos. De acordo com o resultado obtido, verificamos que apenas a variável Lucro Líquido e Patrimônio Líquido estão altamente correlacionadas (0.8421), já o Lucro Líquido e a DTVM (0.6441), e Patrimônio Líquido e DTVM (0.5745) estão de acordo com a média. As demais variáveis possuem um grau baixo de correlação.

A segunda análise parte da matriz de covariância, que exibe os valores de covariância mensurando a relação linear de cada par de variáveis. Os valores de covariância positivos indicam que valores acima da média de uma variável estão associados a valores médios acima da outra variável e que valores abaixo da média de uma variável estão associados com valores abaixo da média de outra variável. Ao contrário, os valores de covariância negativos indicam que valores acima da média de uma variável estão associados com valores médios abaixo da outra variável.

A média do item é a soma de todos os escores de um item dividida pelo número de escores daquele item. A média total é a soma de todas as médias do item. O desvio padrão é a medida mais comum de dispersão, ou o quanto os dados estão dispersos sobre a média. Os resultados elaborados pela matriz de covariância podem ser observados no Quadro 3.

Quadro 3- Matriz de Covariância

\begin{tabular}{|c|c|c|c|}
\hline $\begin{array}{c}\text { Matriz de } \\
\text { covariância }\end{array}$ & N $^{\circ}$ de observações & Média & Desvio Padrão \\
\hline InY & 1147 & 2.4564 & 1.6089 \\
InEMP & 1152 & 3.8020 & 0.6483 \\
InDTVM & 1146 & 4.2693 & 1.4291 \\
InPT & 1152 & -2.4296 & 3.9332 \\
InLL & 1048 & -6.0520 & 3.2775 \\
\hline
\end{tabular}

Fonte: Elaboração própria. 
Baseando-se no teste de Breusch-Pagan, rejeitou-se a hipótese de homocedasticidade, ou seja, o modelo apresentou indícios de heterocedasticidade 5 . Um método simples para resolver o problema foi utilizar a correção robusta de White, o que foi incorporado ao modelo e seus resultados podem ser observados no Quadro 4.

Quadro 4- Resultado da Regressão Econométrica

\begin{tabular}{|c|c|c|c|c|}
\hline $\mathrm{N}^{\circ}$ de observações & 1038 & & & \\
\hline$F(6,1031)$ & 58.32 & & & \\
\hline Prob $>F$ & 0.000 & & & \\
\hline $\mathrm{R}$ quadrado & 0.2917 & & & \\
\hline $\begin{array}{l}\text { Variável dependente } \\
\qquad \ln Y\end{array}$ & Coeficiente & $\begin{array}{l}\text { Erro } \\
\text { padrão }\end{array}$ & Estatística T & $\mathrm{P}$ valor \\
\hline $\ln E M P$ & 0.2853 & 0.0854 & 3.34 & 0.001 \\
\hline InDTVM & 0.4492 & 0.0479 & $9 \cdot 37$ & 0.000 \\
\hline InPT & 0.6856 & 0.0211 & 3.24 & 0.001 \\
\hline InLL & -0.8995 & 0.0276 & -3.25 & 0.001 \\
\hline D1 & 1.7268 & 0.2055 & 8.4 & 0.000 \\
\hline D2 & -1.2129 & 0.1828 & -6.63 & 0.000 \\
\hline constante & -0.9521 & 3836.01 & -2.48 & 0.013 \\
\hline
\end{tabular}

Fonte: Elaboração própria.

A partir dos resultados apresentados na Tabela 4, serão feitas as análises das variáveis explicativas consideradas na modelagem de dados em painel, sob efeitos fixos $^{6}$. A função Cobb-Douglas estimou as elasticidades com a variável dependente receita operacional, utilizando a regra prática 2 -t, acima de 20 graus de liberdade ou mais, se o nível de significância a, for definido em $5 \%$, a hipótese nula pode ser rejeitada se o valor $t$ calculado for maior que 2 em valor absoluto. Desse modo, pode-se observar que todas as variáveis foram estatisticamente significativas. Observa-se também que o baixo nível do valor $\mathrm{p}$, que define o menor nível de significância a que uma hipótese nula pode ser rejeitada, ou a probabilidade exata de cometer o erro Tipo I, rejeitar uma hipótese nula quando esta é verdadeira, não ocorre no modelo apresentado na Tabela 4.

A elasticidade estimada para a variável que representa a aplicação do emprego (InEMP) apresentou um valor positivo de 0,2853, enquanto a elasticidade das inovações financeiras (InDTVM) foi superior a 0,4492. Tal resultado comprova que a lucratividade dos bancos pode ser acrescida mais pela criação de novos produtos e serviços diferenciados do que pela redução de custos operacionais mediante a diminuição de empregados ou melhoria tecnológica (PAULA, 1999; REZENDE, 2012). A variedade tecnológica, assim como, os meios eletrônicos ampliaram o

5 Pelo teste de Breusch-Pagan, rejeitou-se a hipótese de variância constante, indicando a heterocedasticidade do modelo (Chi2(1): 106,21 - p value: 0,0000).

${ }^{6}$ A escolha pelo modelo de efeitos fixos foi feita com base no teste de Hausman, que foi significativo e, portanto, permitiu rejeitar a hipótese nula de que o modelo de efeitos aleatórios é o mais adequado. (Teste de Hausman:68,47 p-value:0,0000 ). 
atendimento ao público nas operações rotineiras (REZENDE, 2012; PAULA, 2014). Desta forma, o emprego destas tecnologias não contribuiu significativamente com aumentos de receita, uma vez que a medida de eficiência do Lucro Líquido, representada pela variável (InLL) foi negativa $(-0,8995)$. Logo, os bancos puderam aumentar seus lucros por meio de produtos e serviços diferenciados sem haver aprimoramento em sua eficiência operacional (REZENDE, 2012).

Segundo Rezende (2012) as inovações financeiras possibilitaram a ampliação dos ativos financeiros estimulando as operações de curto prazo e as especulações, que por sua vez, aumentaram os lucros de forma mais rápida. Desta forma, observou-se que os bancos buscaram maximizar os lucros e direcionaram os seus recursos em aplicações de ativos financeiros. Dada a oferta de créditos de médio e longo prazo, essa não foi a forma mais funcional para o desenvolvimento econômico no país (REZENDE, 2012; FREITAS, 2009).

A elasticidade da proxy das inovações financeiras (InDTVM) $(0,4492)$ foi superior ao valor observado na variável emprego $(\operatorname{InEmp})(0,2853)$ caracterizando, assim, que a lucratividade dos bancos é acrescida mais pela criação de novos produtos e serviços do que pela redução de custos operacionais mediante a diminuição de empregados ou melhoria tecnológica. O resultado observado pode trabalho de Rezende (2012), que demonstra por meio de seus resultados que apesar de várias tecnologias e dos meios eletrônicos que ampliam o atendimento ao público nas operações do dia a dia, o emprego destas tecnologias não contribuiu efetivamente com aumentos de receita. Sendo assim, o valor da elasticidade das inovações financeiras, ter sido superior ao fator de produção trabalho, corrobora com a teoria Pós Keynesiana de que os bancos criam inovações visando os lucros, não a diminuição dos custos (MINSKY, 2010); STUART (1995); PAULA (2008).

Cabe ressaltar ainda que o efeito da variável representativa do patrimônio líquido (InPTL) sob o valor $(0,6856)$ da variável dependente $(\operatorname{lnY})$, demonstrou-se uma relação linear existente na regressão. Em outras palavras, a redução de custos operacionais teve um impacto menor no aumento da lucratividade das instituições bancárias, do que o efeito das inovações financeiras sob a lucratividade das instituições analisadas, como explanado anteriormente. Quanto às variáveis dummies inseridas (D1 e D2), ambas obtiveram resultados significativos, o que confirma a identificação de mudanças estruturais que podem ser atribuídas ao comportamento das instituições financeiras no período sob análise, principalmente antes e após a crise de 2008 (ARAUJO e GENTIL, 2011).

Nesse sentido, é importante ressaltar o contexto econômico nacional para o período da crise de 2008 que tiveram efeitos sobre o sistema bancário. Dois aspectos relacionaram-se com os resultados do setor bancário apresentados anteriormente: os juros altos em meio à crise e valorização do dólar. Segundo Araujo e Gentil, (2011), os efeitos recessivos dos elevados juros que ocorreram ao longo de 2008 foram sentidos muito tardiamente. A lentidão em diminuir a taxa SELIC e a baixa velocidade com o que isto aconteceu provocaram impactos contracionistas na economia. Sob um cenário de incertezas, bancos estrangeiros com filial no Brasil restringiram suas operações no mercado nacional para amenizar os prejuízos em suas matrizes (ARAUJO e GENTIL, 2011). Como consequência, a combinação entre as incertezas e a crise financeira internacional levou o sistema bancário nacional a restringir a sua oferta de crédito, elevando o aumento da 
aversão do risco e a preferência pela liquidez. Tais resultados podem ser observados na resposta da variável proxy que mede a eficiência do Lucro Líquido, em que obteve sinal negativo evidenciando o cenário de crise em virtude da desaceleração econômica.

Com relação à valorização do dólar, esta foi marcada pelos efeitos sobre as reservas internacionais. A redução do valor das reservas ocorreu devido a perda do valor do ativo em função do câmbio valorizado (ARAUJO e GENTIL, 2011) Desse modo, a redução do valor do ativo reservas internacionais aumentou a dívida líquida total do setor público. Como resultado para a economia assim como para o sistema bancário brasileiro, a expansão do endividamento público restringiu o crédito e os investimentos públicos.

Ademais, no âmbito regional, os resultados convergem com a discussão realizada anteriormente na seção 3. Em outras palavras, observou-se que o sistema bancário brasileiro acompanhou, no período sob estudo, o movimento de intensificação das inovações financeiras globalizado, propiciando ao mercado condições para que as concentrações espaciais fossem aprimoradas (Marshall, 1982; Audretsch e Feldman, 1996; Silva, 2011) e possibilitassem o desenvolvimento de serviços inovadores para o sistema bancário (FONSECA, MEIRELES e DINIZ, 2010). O sinal e a significância da variável proxy das inovações financeiras evidenciam que houve um estímulo pelo sistema bancário em potencializar as oportunidades do setor financeiro. Do mesmo modo, o resultado confirma a lógica de que a informação que é gerada nos centros urbanos potencializa o melhor acesso às explorações lucrativas, especialmente por parte dos fluxos financeiros (SILVA, 2011).

Resultados mais específicos sobre os efeitos regionais e, uma análise mais detalhada sobre o modo como esses efeitos da crise podem ter contribuído ou minimizado as disparidades regionais, poderão ser observados em futuras extensões do presente trabalho.

\section{Considerações Finais}

O presente artigo analisou as contribuições das TICs nos fatores de produção sob o sistema bancário brasileiro desde o primeiro trimestre do ano de 2001, até o quarto trimestre de 2016, dando ênfase ao período da crise mundial de 2008. A amostra abrangeu os dezoito maiores bancos brasileiros no período em questão. O trabalho teve como base a teoria Pós Keynesiana, no qual discute a importância de os bancos criarem inovações visando os lucros e, que as TICs possuem relação direta sobre a diminuição da assimetria de informação e da incerteza. Além disso, são importantes na capacidade e na eficiência atribuída aos bancos, principalmente em períodos de aumento pela preferência da liquidez, como foi o caso do período da crise. No momento em questão, a liquidez só voltou ao normal no final do primeiro trimestre de 2009, quando o governo decidiu garanti-la, mediante o Fundo Garantidor de Crédito.

Entre os principais resultados obtidos pela estimação do modelo de efeito fixo de dados em painel, verificou-se que o modelo robusto identificou alterações no ciclo econômico do período. Em outras palavras, o resultado observado propõe que os bancos devem aumentar a sua diversificação para captação de investimentos a curto e a longo prazo para a propagação das inovações financeiras, como as TICs. A 
propósito, as TICs demandam custos elevados e um alto volume de recursos, além do longo período de tempo para o seu retorno.

É oportuno ressaltar que toda inovação tecnológica tem seus custos e demanda um volume de recursos elevado. Contudo, as inovações financeiras se tornaram essenciais à dinâmica econômica de qualquer economia, sendo cada vez mais utilizada pelo maior nível de eficiência alcançado pelas instituições. Apesar dos valores relativamente baixos obtidos pelas regressões, não se pode negar sua influência no sistema, seja por meio de ativos físicos como computadores, ou intangíveis como programas computacionais.

Destaca-se ainda a restrição da base de dados e a assimetria de informações sobre todas as instituições financeiras brasileiras. No entanto, cumpriu-se com o objetivo do trabalho de avaliar a influência da tecnologia no sistema financeiro em períodos de crise, especialmente a de 2008. Os efeitos assimétricos da crise sobre as medidas de eficiência consideradas neste estudo ressaltaram a importância de se analisar tanto a eficiência de custo como a eficiência de lucro. A média dos custos realizados em TICs não foi oferecida pelas instituições de forma específica, como já acontece nos EUA e na Austrália, por exemplo, impossibilitando o sucesso dos estudos brasileiros nessa área.

A abordagem da teoria Pós Keynesiana demonstrou a importância do sistema bancário em uma economia monetária de produção, para explicar como as mudanças no comportamento e das estratégias afetaram as instituições. Com base no circuito Finance-Investimento-Poupança-Funding (FISF), elaborado por Keynes, desenvolveu-se uma visão do papel dos bancos e dos mercados financeiros no processo de crescimento econômico, isto é, a sua funcionalidade. Além disso, verificou-se que a tecnologia da informação e comunicação viabilizou a criação de inovações financeiras, alterando a relação finance/funding originalmente formulada por Keynes.

Outro fator muito importante observado na pesquisa em relação à tecnologia da comunicação e informação, refere-se à redução das assimetrias de informação e o aumento da liquidez dos ativos. As inovações foram criadas para obter vantagens competitivas, de forma a produzir produtos e serviços diferenciados. Além disso, as inovações financeiras foram usadas como instrumentos de gestão das contas financeiras, de forma a flexibilizar as operações financeiras. Dentre os efeitos da Tecnologia da informação e comunicação, a criação de inovações financeiras representou maior relevância no que tange aos aspectos da redução de custos pelas instituições financeiras brasileiras sob análise.

Por fim, este artigo representa um esforço e uma contribuição para pesquisas futuras nesta área. As contribuições do artigo para a ciência permitem avaliar de que maneira o sistema bancário foi afetado pela crise de 2008. Desse modo, observa-se que para o enfrentamento de crises, o sistema bancário deve atentar-se para a restrição de crédito ao consumidor, a reversão das expectativas perante o agravamento da crise financeira internacional e seu efeito "contágio", isto é, o comportamento da crise em relação às economias em desenvolvimento.

As limitações da pesquisa encontradas tanto na base de dados quanto na disponibilidade de variáveis que refletissem, especificamente, a inovação no sistema bancário brasileiro restringiu uma análise mais aprofundada sobre o tema. Ressalta- 
se ainda que a discussão se encontra em estágios iniciais e a análise do indicador de funcionalidade necessita de maior aprofundamento, principalmente quanto à questão do sistema bancário, além de dados relevantes sobre a inovação financeira do setor bancário brasileiro. Para futuras contribuições, é oportuno uma análise mais aprofundada sobre o comportamento de economias emergentes, as relações dos impactos da aplicação de políticas monetárias pelo Banco Central e a dinâmica do setor bancário, assim como Brasil, no enfrentamento de crises. Após a crise de 2008, a dinâmica concorrencial bancária favoreceu o desenvolvimento de tecnologias mais avançadas e, possibilitou a diversificação de negócios, investimentos e crédito. Os próximos estudos têm por objetivo analisar o impacto das inovações das instituições financeiras nas economias em desenvolvimento.

\section{REFERÊNCIAS}

AIDAR, GABRIELA LIMA. Teoria da Firma sob a perspectiva Pós-Keynesiana. Dissertação. Programa de Pós-graduação em Economia da Universidade Federal de Uberlândia. 2015.

ALBERINI, DANIEL VINÍCIUS., BOGUSZEWSKI, LEONARDO DEEKE. Por dentro do subprime: a crise imobiliária americana e seus impactos na economia brasileira. Vitrine da Conjuntura, Curitiba, v. 1, n. 2, p. 1-10, 2008.

ARAUJO, VICTOR LEONARDO DE., GENTIL, DENISE LOBATO. AvançOs, recuos, acertos e erros: uma análise da resposta da política econômica brasileira à crise financeira internacional. Texto para discussão 1602. Rio de Janeiro: IPEA, mar. 2011.

AUDRETSCH, DAVID B., FELDMAN, MARYANN P. R\&D spillovers and the geography of innovation and production. American Economic Review, v. 86, n. 3, p. 630-640, jun. 1996.

BRASIL, Banco. Central. do. IF.DATA. 2018. Disponível em:<https://www3.bcb.gov.br/ifdata/>.

BRESSER-PEREIRA, LUIZ CARLOS. A Crise financeira global e depois: um novo capitalismo? Novos Estudos, São Paulo, v. 86, p. 51-72, 2010. Disponível em: <http://www.scielo.br/pdf/nec/n86/n86a03>. Acesso em: 19 fev. 2020.

DE FREITAS, MARIA CRISTINA PENIDO. Os efeitos da crise global no Brasil: aversão ao risco e preferência pela liquidez no mercado de crédito. Estudos Avançados, v. 23, n. 66, p. 125-145, 2009.

ERBER, FÁBIO STEFANO. O sistema de inovações em uma economia monetária: uma agenda de pesquisas. Globalização \& Inovação Localizada. Experiências de Sistemas Locais no Mercosul. IBICT/MCT, Brasília, 1999.

FONSECA, CARLOS EDUARDO CORREA DA., MEIRELLES, FERNANDO DE SOUZA., DINIZ, EDUARDO HENRIQUE. Tecnologia Bancária no Brasil: uma história de 
conquistas, uma visão de futuro. São Paulo: FGVRAE, 420p. 2010.

JUNIOR, GILBERTO RODRIGUES BORÇA., TORRES FILHO, ERNANI TEIXEIRA. Analisando a crise do subprime. Revista do BNDES. Rio de Janeiro, v. 15, n. 30, p. 129-159, 2008.

KEYNES, JOHN MAYNARD. A teoria geral do emprego, do juro e da moeda. São Paulo: Nova Cultural, 1988. 283 p. (Os economistas).

MAINETTI Jr, SERGIO ; GRAMANI, MARIA CRISTINA NOGUEIRA.; BARROS, HENRIQUE M. Despesas com Tecnologia da Informação e Eficiência Organizacional: Novas Evidências do Setor Bancário Brasileiro. Revista de Administração e Inovação 11, n. 1 (janeiro/março 2014): 138-161.

MARRA, VINICIUS NOGUEIRA; WERPEL, FRANCISCO JOSÉ FONTES. O labirinto da crise financeira de 2008. Idea, v. 2, n. 2, 2011.

MARSHALL, ALFRED. Princípios de Economia. São Paulo: Abril Cultural, p. 231-238, 1982.

MINSKY, HYMAN P. Estabilizando uma economia instável. Osasco: Novo Século, 2010. 455 p. n. 2, 2011.

MONTENEGRO, ROSA LIVIA GONÇALVES; DINIZ, BERNARDO PALHARES CAMPOLINA; SIMÕES, RODRIGO FERREIRA. Ciência e Tecnologia versus estruturas estaduais: uma análise em dados em painel (2000-2010). Anais do XLII Encontro Nacional de Economia. ANPEC-Associação Nacional dos Centros de Pós-graduação em Economia (2014).

PAULA, LUIZ FERNANDO. Preferência pela liquidez e a natureza da 'crise'brasileira. Dossiê da crise. Porto Alegre: Associação Keynesiana Brasileira, Programa de PósGraduação em Economia da Universidade Federal do Rio Grande do Sul, p. 64-68, 2008.

PAULA, LUIZ FERNANDO. Sistema Financeiro, bancos e financiamento da economia: uma abordagem keynesiana. Campus/Elsevier, Rio de Janeiro. 2014. PAULA, LUIZ FERNANDO. Teoria da firma bancária. LIMA, G. T. et all.

Macroeconomia moderna: Keynes e a economia contemporânea. Rio de Janeiro: Campus, 1999. PESSALI, HUÁSCAR; FERNANDEZ, RAMÓN. Inovação e teorias da firma. In: PELAEZ, Victor; SZMRECSÁYI, Tamás. Economia da Inovação Tecnológica. São Paulo: HUCITEC, 2006.

PINDYCK, ROBERT S.; RUBINFELD, DANIEL. Econometria Modelos e Previsões. Rio de Janeiro: Elsevier, 2004. 
REZENDE, LUIZ PAULO. Fontes de Inovação tecnológica e a funcionalidade do sistema financeiro: uma análise de balanço patrimonial dos bancos no Brasil. Tese de Doutorado. Universidade Federal de Minas Gerais. 2012

RODRIGUEZ-FUENTES, CARLOS J., DOW, SHEILA. C. EMU and the Regional Impact of Monetary Policy. Regional Studies, v. 37.9, p. 969-980, dezembro de 2003.

SCHUMPETER, JOSEPH A. Teoria do desenvolvimento econômico: Uma investigação sobre lucros, capital, credito, juro e o ciclo econômico. 3 ed. São Paulo: Nova Cultural, 1988. 169 p. (Os economistas).

SILVA, FERNANDA FARIA. Centralidade e impactos regionais de política monetária: um estudo dos casos brasileiro e espanhol. Tese(doutorado) -Universidade Federal de Minas Gerais, Centro de Desenvolvimento e Planejamento Regional. 293f. 2011.

WOOD, PETER. Conclusions: innovative cities in Europe. In: SIMMIE, J. (Ed.), Innovative cities. New York: Spon Press, p. 231-247, 2001.

WOOLDRIDGE, JEFFREY M. Introdução à Econometria: uma abordagem moderna. [S.I.]: São Paulo: Cengage Learning, 2014.

Rosa Livia Gonçalves Montenegro. Doutora pela Universidade Federal de Minas Gerais (UFMG). Professora Adjunta na Universidade Federal de Juiz de Fora (UFJF). Rua José Lourenço Kelmer, São Pedro - Cidade Universitária, Cep: 36036330 - Juiz de Fora, MG - Brasil. E-mail: rosa.livia@ufjf.br

Mariana Carolina da Silva. Economista pela Universidade Federal de São João del Rei. Campus Tancredo Neves - CTAN. Avenida Visconde do Rio Preto, Km 02 Prédio Ciências Econômicas - São João del Rei, MG - Brasil. E-mail: mcarolsilva92@gmail.com

Fernanda Espiridião. Doutora pela Universidade Federal do Paraná (UFPR). Professora Associada da Universidade Federal de Sergipe (UFS). Cidade Universitária Prof. José Aloísio de Campos Jardim Rosa Elze. Cep: 49100000 Aracaju, SE - Brasil. E-mail: esperidiao@ufs.br

Douglas Marcos Ferreira. Doutor pela Universidade Federal de Viçosa (UFV). Professor Adjunto da Universidade Federal de São João del Rei (UFSJ). Campus Tancredo Neves - CTAN. Avenida Visconde do Rio Preto, Km 02 - Prédio Ciências Econômicas - São João del Rei, MG - Brasil. E-mail: douglasferreira@ufsj.edu.br 
Como citar: MONTENEGRO, Rosa Livia Gonçalves et al. Influência da crise financeira de 2008: uma análise sobre a tecnologia da informação dos maiores bancos do consolidado financeiro brasileiro (2001-2016). Redes (St. Cruz Sul, Online), Santa Cruz do Sul, v. 25, p. 2454-2476, 2020. ISSN 1982-6745. doi:https://doi.org/10.17058/redes.v25io.14978.

\section{CONTRIBUIÇÃO DE CADA AUTOR}

1) Conceituação (Conceptualization): Mariana da Silva , Rosa Montenegro e Fernanda Espiridião.

2) Curadoria de Dados (Data curation): Mariana da Silva

3) Análise Formal (Formal analysis): Rosa Montenegro, Fernanda Espiridião e Douglas Ferreira.

4) Investigação/Pesquisa (Investigation): Rosa Montenegro, Mariana da Silva, Fernanda Espiridião e Douglas Ferreira.

5) Metodologia (Methodology): Rosa Montenegro, Mariana da Silva e Douglas Ferreira.

6) Supervisão/orientação (Supervision): Rosa Montenegro

7) Escrita - Primeira Redação (Writing - original draft): Rosa Montenegro, Mariana da Silva, Fernanda Espiridião e Douglas Ferreira.

8) Escrita - Revisão e Edição (Writing - review \& editing): Rosa Montenegro, Mariana da Silva, Fernanda Espiridião e Douglas Ferreira.

Fontes de financiamento: Este trabalho contou com financiamento do CNPq, por meio de bolsa de Iniciação Científica do EDITAL N ${ }^{\circ}$ 003/2017/PROPE - PROGRAMA INSTITUCIONAL DE BOLSAS DE INICIAÇÃO CIENTÍFICA -PIBIC/CNPq/UFSJ. Orientadora: Profa. Rosa Livia Gonçalves Montenegro. Orientanda: Mariana Carolina da Silva 